\title{
Badania skłonności do pęknięć gorących metodą Blanchet’a
}

\section{Evaluation of hot crack susceptibility by the Blanchet method}

\section{Streszczenie}

W artykule przedstawiono wyniki oceny skłonności do pęknięć gorących dwóch stopów niklu 600 i 617. Próby przeprowadzono na blachach cienkich $(1 \mathrm{~mm})$ wykorzystując metodę Blanchet'a. Uzyskane wyniki wskazują na skłonność badanych materiałów do pęknięć gorących przy określonym stopniu odkształceń i naprężeń. Pęknięcia zlokalizowane są w obszarze stało-ciekłym. Nie zaobserwowano ich występowania w dalszej części spoiny.

Słowa kluczowe: stopy niklu; pęknięcia gorące; spawanie
Abstract

The paper shows the results of hot crack susceptibility tests of 600 and 617 nickel alloys. The thin plates $(1 \mathrm{~mm})$ in the Blanchet method were used for tests. The increase of hot crack susceptibility of tested alloys with strain and stress is obtained in the mushy zone $(S+L)$. In the other areas of weld metal the cracks were not observed.

Keywords: nickiel alloys; hot crack; welding

\section{Wstęp}

Wymagania pracy urządzeń w podwyższonej temperaturze i korozyjnym środowisku stawiają inżynierom-konstruktorom i technologom zadanie doboru materiałów inżynierskich wykazujących wysokie właściwości mechaniczne. Takie wymagania spełniają m.in. stale austenityczne i stopy na osnowie niklu, co powoduje, że są one stosowane w przemyśle lotniczym, kosmicznym, chemicznym oraz energetyce $[1 \div 4]$. Szczególne zainteresowanie stopami niklu wynika z ich unikalnych właściwości związanych z zachowaniem wysokiej wytrzymałości i odporności na pełzanie w wysokiej temperaturze (nawet do $1100{ }^{\circ} \mathrm{C}$ ) oraz odporności na korozję w agresywnych środowiskach - chlorków, związków siarki i azotu, czy fluoru $[4,5]$. W pracy przedstawiono ocenę skłonności do pęknięć gorących wybranych stopów niklu.

W celu przeprowadzenia oceny skłonności do pęknięć gorących wybranych stopów niklu opracowano program badań obejmujący. ocenę składu chemicznego z wykorzystaniem spektrometrii iskrowej, ocenę mikrostruktury z wykorzystaniem mikroskopii świetlnej i przeprowadzenie oceny skłonności do pęknięć gorących blach cienkich (1 mm) w próbie Blanchet'a.

\section{Materiał do badań}

Do badań użyto dwóch stopów niklu utwardzanych roztworowo o oznaczeniach 600 i 617 , których skład chemiczny zawarto w tabeli I. Szczegółowy skład chemiczny zawierający również mikrododatki stopowe wskazano wg danych materiałowych Bibus Metals. Dodatkowo wykonano badanie przy użyciu spektrometru XRF, które wykazało obecność jedynie czterech głównych pierwiastków stopowych. Wyniki
Tablica I. Skład chemiczny stopu 600 i 617 wg danych Bibus Metals, $\%$ wag

Table I. Chemical composition of 600 and 617 nickel alloys acc. to Bibus Metals data, wt. \%

\begin{tabular}{|c|c|c|c|c|}
\hline \multirow{2}{*}{$\begin{array}{c}\text { Pierwiastek } \\
\text { stopowy }\end{array}$} & \multicolumn{2}{|c|}{600} & \multicolumn{2}{|c|}{617} \\
\hline & $\begin{array}{l}\text { Wg. Bibus } \\
\text { Metals }\end{array}$ & $\begin{array}{c}\text { Spektrometr } \\
\text { XRF }\end{array}$ & $\begin{array}{l}\text { Wg. Bibus } \\
\text { Metals }\end{array}$ & $\begin{array}{c}\text { Spektrometr } \\
\text { XRF }\end{array}$ \\
\hline Al & $\max 0,3$ & & $0,8-1,5$ & \\
\hline B & $\max 0,006$ & & $\max 0,006$ & \\
\hline C & $0,05-0,15$ & & $0,05-0,15$ & \\
\hline Co & & & $10-15$ & 11 \\
\hline $\mathrm{Cr}$ & $14-17$ & 16,2 & $20-24$ & 23,9 \\
\hline $\mathrm{Cu}$ & $\begin{array}{c}\max \\
0,1 / 0,5\end{array}$ & & $\max 0,5$ & \\
\hline $\mathrm{Fe}$ & $6-10$ & 10 & $\max 3,0$ & 1 \\
\hline Mn & $\max 1$ & & $\max 1,0$ & \\
\hline Mo & & & $8-10$ & 8,5 \\
\hline $\mathrm{Ni}$ & $\min 72$ & 73,4 & $\min 44,5$ & 55,4 \\
\hline $\mathbf{P}$ & $\max 0,015$ & & & \\
\hline$S$ & $\begin{array}{c}\max 0,002 \\
(15)\end{array}$ & & $\max 0,015$ & \\
\hline Si & $\begin{array}{c}\max \\
0,2 / 0,5\end{array}$ & & $\max 1,0$ & \\
\hline $\mathrm{Ti}$ & $\max 0,3$ & 0,3 & $\max 0,6$ & \\
\hline
\end{tabular}

Dr inż. Lechosław Tuz; mgr inż. Krzysztof Pańcikiewicz - AGH Akademia Górniczo-Hutnicza w Krakowie; dr hab. inż. Janusz Adamiec, prof. PŚl - Politechnika Śląska.

Autor korespondencyjny/Corresponding author. Ituz@agh.edu.pl 
pomiaru wskazują zgodność składu chemicznego w obszarze tych pierwiastków z danymi producenta.

Próbki do oceny skłonności do pęknięć gorących wycinano z blach o grubości $1 \mathrm{~mm}$.

Wykorzystane do badań stopy niklu są stopami wieloskładnikowymi różniącymi się zawartością głównych pierwiastków stopowych tzn. niklu, kobaltu, chromu i molibdenu. Stop 600 to stop o dużej zawartości niklu, który zapewnia wysoką odporność stopu na korozję w środowisku bogatym w elementy zarówno organiczne jak i nieorganiczne, jak również na korozję naprężeniową. Chrom powoduje poprawę odporności na korozję w podwyższonej temperaturze (tworzy się warstwa tlenków), jak również chroni go przed negatywnym działaniem siarki. Jego obecność sprzyja formowaniu się węglików $\mathrm{M}_{7} \mathrm{C}_{3}$, a w połączeniu z molibdenem $\mathrm{M}_{23} \mathrm{C}_{6}$, powodujących poprawę właściwości mechanicznych stopu, gdyż nie tworzą ciągłej siatki po granicach ziarn. W stopie 617, obniżono zawartość niklu, zwiększając zawartość chromu i wprowadzając dodatek kobaltu. Chrom i aluminium w tym stopie powodują wzrost odporności na utlenianie i nawęglanie w podwyższonej temperaturze tworząc warstwę ochronną na powierzchni $\left(\mathrm{Cr}_{2} \mathrm{O}_{3}, \mathrm{Al}_{2} \mathrm{O}_{3}\right)$ i zapobiegają wnikaniu tlenu w materiał, a dodatek molibdenu pozwala na stosowanie go w środowisku wilgotnym. Połączenie molibdenu i kobaltu powoduje roztworowy charakter umacniania stopu.

\section{Ocena makro- i mikrostruktury}

Ocenę makrostruktury przeprowadzono na zgładach metalograficznych blach o grubości $5 \mathrm{~mm}$, które poddano działaniu spawalniczego cyklu cieplnego. Próby spawania przeprowadzono metodą TIG stosując argon jako gaz osłonowy. Przeprowadzone próby miały wskazać kształt wtopienia i jego głębokość przy różnych wartościach natężenia prądu. Próby te były niezbędne dla doboru parametrów spawania podczas wykonywania prób oceny skłonności do pęknięć gorących.

$\mathrm{Na}$ rysunku 1 przedstawiono kształt wtopienia i wyniki pomiarów szerokości lica i głębokości wtopienia przy różnej wartości natężenia prądu. Widoczny jest znaczny wzrost szerokości lica, a jedynie nieznaczny wzrost głębokości wtopienia wraz ze wzrostem natężenia prądu. Wynika to z niskiej przewodności cieplnej stopu i dużej gęstopłynności ciekłego metalu. Duża gęstopłynność utrudnia nagrzewanie metalu przy dnie jeziorka spawalniczego przez ograniczoną cyrkulację ciekłego metalu. Ujawnione próby wykazują jednoznacznie, że dla materiałów o grubości powyżej $2 \div 3 \mathrm{~mm}$ należy stosować spawanie wielościegowe z ukosowaniem brzegów lub skoncentrowane źródła ciepła.
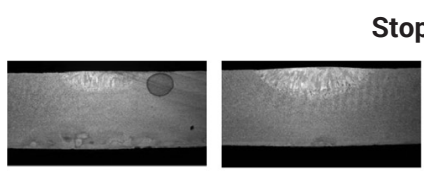

Stop 600

Głębokość wtopienia: Głębokość wtopienia: Głębokość wtopienia: Głębokość wtopienia: $1 \mathrm{~mm}$ $1,5 \mathrm{~mm}$
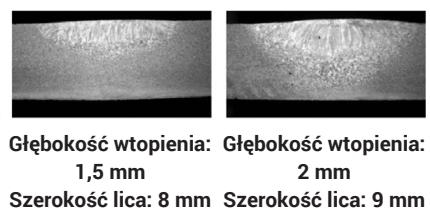

Szerokość lica: 4,5 mm Szerokość lica: 5 mm Szerokość lica: 8 mm Szerokość lica: $9 \mathrm{~mm}$
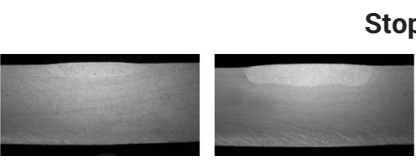

Stop 617

Głębokość wtopienia:
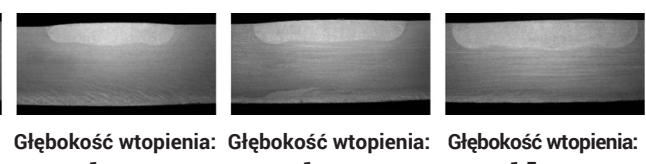

$$
0,7 \mathrm{~mm}
$$

$$
1 \mathrm{~mm}
$$$$
1 \mathrm{~mm}
$$

$1,5 \mathrm{~mm}$

Szerokość lica: $4 \mathrm{~mm}$ Szerokość lica: 5,5 mm Szerokość lica: $8 \mathrm{~mm}$ Szerokość lica: $10 \mathrm{~mm}$

Rys. 1. Makrostruktury wtopień. Wpływ natężenia prądu spawania na kształt wtopienia stopu 600 i 617

Fig. 1. Macrostructure of melted metal. Influence of welding current on the shape of melted metal of 600 and 617 nickel alloys

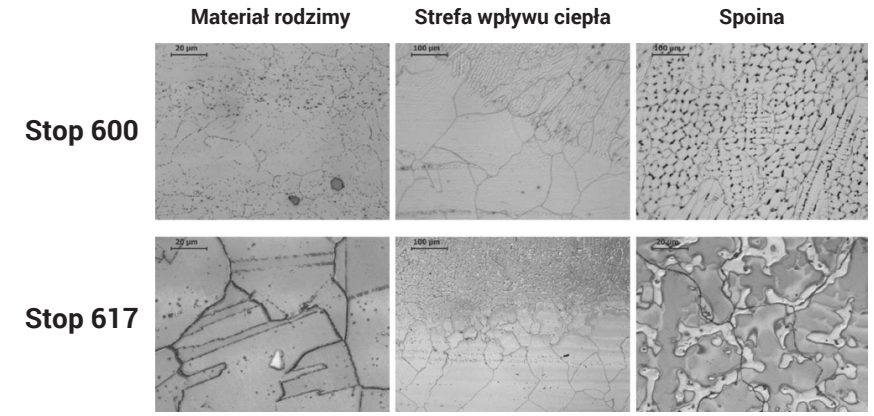

Rys. 2. Mikrostruktura stopów 600 i 617 w charakterystycznych obszarach złącza spawanego

Fig. 2. Microstructure of 600 and 617 nickel alloys in the specific areas of welded joint

\section{Ocena skłonności do pęknięć gorących}

Metoda Blanchet'a stosowana jest do oceny skłonności do pęknięć gorących blach cienkich. Wykorzystywane są próbki kołowe mocowane sztywno w specjalnym uchwycie. Zadawane jest początkowe odkształcenie (naprężenie) kulistym trzpieniem, którego miarą jest wygięcie wstępne (strzałka wygięcia), a następnie prowadzony jest proces pierścieniowego napawania lub przetapiania materiału rodzimego o minimalnej średnicy $60 \mathrm{~mm}$. Uzyskany stan naprężeń odpowiada modelowi wytrzymałościowemu płyty utwierdzonej na obwodzie na którą działa siła skupiona F. Wadą próby jest zmienny stan naprężeń, tzn. wstępny stan naprężeń nie jest ściśle określony i zmienia się podczas spawania. Wstępne naprężenie można wyznaczyć ze wzoru (1).

$$
\sigma=\frac{3 F}{2 \pi g^{2}}\left(1-\frac{b^{2}}{a^{2}}\right)
$$

gdzie:

b - średnica trzpienia stykającego się z powierzchnią blachy, mm; a - średnica próbki liczona od krawędzi zamocowania, mm; F - siła skupiona, N; g - grubość blachy, mm.

Miarą odporności na pękanie gorące jest wartość strzałki wstępnego wygięcia próbki, przy której podczas spawania pojawiają się pęknięcia. Schemat prowadzenia badania przedstawiono na rysunku 3.

Próby przeprowadzono z wykorzystaniem specjalnego przyrządu do oceny skłonności do pęknięć gorących metodą Blancheta zamontowanego na obrotniku spawalniczym. Próbki o średnicy $136 \mathrm{~mm}$ pobrane z blach o grubości $1 \mathrm{~mm}$ przetapiano łukiem elektrycznym metodą TIG w osłonie gazów ochronnych. Stałymi parametrami procesu spawania było natężenie wypływu gazu ochronnego $12 \mathrm{l} / \mathrm{min}$ (argon 4,8), natężenie prądu spawania $50 \mathrm{~A}$, napięcie łuku (ok. $23 \mathrm{~V}$ ) i długość łuku ok. 1,5 mm. Zmiennym parametrem w próbie była prędkość liniowa spawania ustalana na obrotniku.

Zestawienie wyników próby zamieszczono rysunkach 4 i 5 . Przeprowadzone próby pozwoliły na wyznaczenie obszaru parametrów spawania i dopuszczalnego odkształcenia (naprężenia) materiału rodzimego dla którego nie występują pęknięcia gorące. W stopie 600 nie stwierdzono występowania pęknięć gorących.

Dodatkowo, dla uzyskanych wyników opracowano wskaźnik pękania (W). Wartość wskaźnika ustalono w następujący sposób:

- $W$ = 1 dla próbki bez pęknięć,

$W=1+\frac{2 \alpha}{360}$

- dla próbki z pęknięciem z zakresu od $0^{\circ}$ do $360^{\circ}$, gdzie:

a - długość kątowa pęknięcia,

- $\mathrm{W}=3$ dla próbki z pęknięciem na całym obwodzie koła. 
Zastosowanie wskaźnika pękania pozwoliło na wyznaczenie obszarów bez pęknięć, z krótkimi pęknięciami i pęknięciami kołowymi. Pęknięć kołowych dla stopu 600 i 617 nie obserwowano, ponieważ próbka podczas zadawania zbyt dużych wartości wygięcia wstępnego (naprężenia i dokształcenia) ulegała pofalowaniu. Wyniki w formie wykresów przedstawiono na rysunku 5.

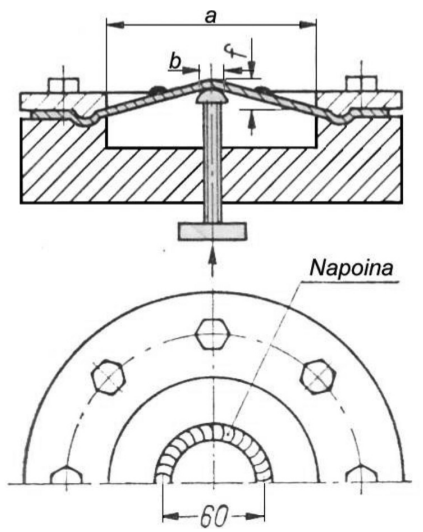

Rys. 3. Schemat prowadzenia prób oceny skłonności do pęknięć gorących metodą Blancheta

Fig. 3. Scheme of hot crack susceptibility evaluation by the Blanchet method
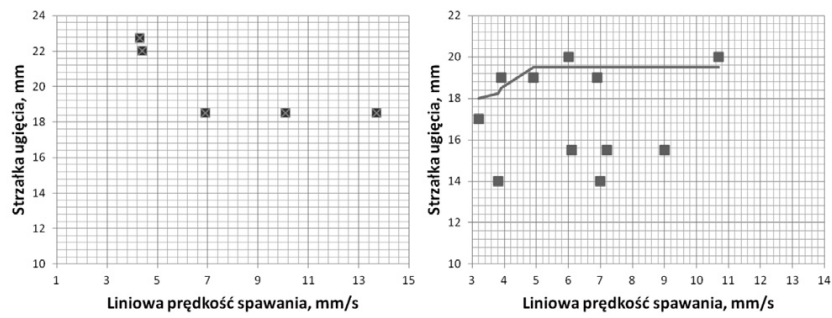

Rys. 4. Wyniki pomiarów skłonności do pęknięć gorących metodą Blancheta stopu a) 600 - brak pęknięć, b) 617. Obszar powyżej krzywej łamanej - obszar skłonności do pęknięć gorących

Fig. 4. Hot crack susceptibility results received by Blanchet method for. a) 600 alloy (lack of cracks), b) 617 alloy. Hot cracking in the area over the line
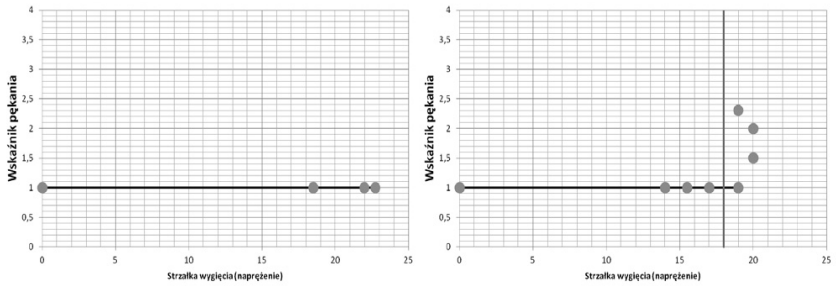

Rys. 5. Zależność wskaźnika pękania od strzałki wygięcia (naprężenia) dla stopu a) 600 , b) 617

Fig. 5. The cracing ratio in the function of deflection (stress) for. a) 600 alloy, b) 617 alloy

\section{Podsumowanie}

Przeprowadzona analiza skłonności do pęknięć gorących stopów niklu typu 600 i 617 wykazała, że charakteryzują się one znaczną skłonnością do pęknięć gorących podczas spawania w warunkach dużych naprężeń:

- dla stopu 617 wyznaczono obszary w funkcji odkształcenia i prędkości spawania, w których pęknięcia występują. Nie uzyskano pęknięć na całym obwodzie wtopienia, ponieważ obszar występowania tego typu pęknięć znajduje się poza zakresem pomiarowym przyrządu.

- ze wzrostem odkształcenia zaobserwowano wzrost skłonności do pęknięć gorących badanych stopów. Pęknięcia powstają w obszarze stało-ciekłym, w którym następuje wzrost dendrytów w cieczy metalicznej. Obecność ciekłego metalu pomiędzy dendrytami powoduje obniżenie plastyczności i wytrzymałości metalu będącego już w stanie stałym.

Publikacja powstała w ramach pracy statutowej 11.11.110.299

\section{Literatura}

[1] Song K.H., Nakata K.: Effect of precipitation on post-heat-treated Inconel 625 alloy after friction stir welding, Materials and Design, 31 (2010), s. $2942 \div 2947$.

[2] Yenia C., Koc-akb M.: Fracture analysis of laser beam welded superalloys Inconel 718 and 625 using the fitnet procedure, International Journal of Pressure Vessels and Piping, 85 (2008), s. 532 $\div 539$.

[3] Yilbas B.S., Akhtar S.S., Karatas C.: Laser surface treatment of Inconel 718 alloy:Thermal stress analysis, Optics and Lasers in Engineering, 48 (2010), s. $740 \div 749$.
[4] Pakieła Z.: Microstructure and mechanical properties of Inconel 625 superalloy, Obróbka Plastyczna Metali, t. XXI, 3 (2010), s. 143 $\div 154$.

[5] Huang C.A., Wang T.H.,. Han W.C, Lee C.H.: A study of the galvanic corrosion behavior of Inconel 718 after electron beam welding, Materials Che-

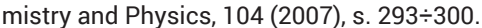

[6] Tasak E., Ziewiec A.: Spawalność materiałów konstrukcyjnych Tom 1 Spawalność stali, Wydawnictwo JAK, Kraków 2009. 